\title{
Entre espinas, flores y palmas: corta de la flor de Corozo y Coyol en Izalco
}

\author{
Among thorns, flowers and palms: the harvest of the corozo flower \\ and coyol ${ }^{2}$ in Izalco
}

\section{ISSN 2071-8748 \\ E-ISSN 2218-3345

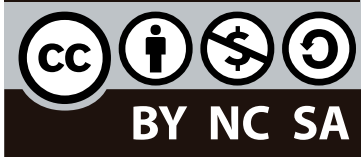

DOI: https://doi.org/10.5377/entorno.v0i68.8454

URI: http://hdl.handle.net/11298/1134

\author{
Carlos Felipe Osegueda \\ carlos.osegueda@utec.edu.sv \\ ORCID: 0000-0002-7003-1043 \\ Miguel Angel Hernández \\ miguelangeles79@gmail.com \\ Instructor \\ Miguel Ángel Najo-Latin ${ }^{3}$ \\ mtd.hini@gmail.com \\ Estudiante Utec \\ Francisco Enrique Santos-Alvarenga ${ }^{4}$ \\ mtd.hini@gmail.com \\ Estudiante Utec \\ Recibido: 2 de abril 2019 \\ Aprobado: 4 de julio 2019
}

\section{Resumen}

Uno de los objetivos de la investigación, es poder registrar y analizar diversas prácticas que giran en torno a la hermandad de Jesús Nazareno, y una acción de lo más importantes es la corta de la flor de corozo y coyol, que a pesar de ser una práctica con gran arraigo identitario es poco conocida, ello forma parte de un gran entretejido de símbolos que otorga a la población un sentido de pertenencia y por medio de ello los significados varían según la percepción individual de los devotos a Jesús Nazareno, generando así en la otredad una amalgama de emociones y comportamiento socioculturales en el municipio de Izalco.

\section{Palabras clave}

Ritos de semana santa - Izalco, El Salvador. Ritos y ceremonias - Izalco, El Salvador. Festividades religiosas - Izalco, El Salvador. Etnología - El Salvador

\section{Abstract}

One of the objectives of this research is to be able to record and analyze a diversity of practices around the Hermandad de Jesús de Nazareno (the brotherhood of Jesus of Nazareth). One of the most relevant activities is the harvest of the corozo flower and the coyol, which in spite of being a practice with strong identity roots, is not very well known; it is part of an interweaving of symbols which gives the population a sense of belonging, and through this, the meanings vary depending on the individual perception of the devouts to Jesús Nazareno, thus generating in others a fusion of emotions and sociocultural behaviors in the municipality of Izalco.

\section{Keywords}

Holy Week Rites/Traditions - Izalco, El Salvador. Rituals and ceremonies- Izalco, El Salvador. Religious Festivities - Izalco, El Salvador. Ethnology - El Salvador. 


\section{Introducción}

Uno de los elementos míticos que dotan de aroma en la cuaresma y Semana Santa, es la flor de coyol y el corozo, que son un elemento infaltable dentro de los actos de piedad popular, ya que su presencia armoniza la celebración o ritualidad, tanto en las velas de Jesús como en el adorno de los cristos, dando así sentido y significado a un todo.

El coyol (nahuatlismo de coyolli, 'palmera' o 'cascabel') es una palmera cargada de espinas, que puede llegar a medir de 10-15 metros de altura y usualmente está rodeado de palos de ishcanal (escanal, ishcanal), arbustos de güistomate y epasina, los cuales junto a las palmeras forman una gran cantidad de espinas, creando en medio de los barrancos una alfombra de espinas, que demandan una gran agilidad para poder alcanzar la flor del coyol, así como los cojollos, que sirven para hacer las cruces de los cristos, siendo la corta de la flor y su entrega un acto ritual en el que el cortador pasa por un proceso de sacrificio dando paso a la fe y ser percibida por el olor de dicha flor.

\section{Entretejido simbólico}

Las expresiones culturales dependen de la figuración o construcción de algo material que permita ser el hilo conductor de la devoción y de la cultura en general. Por tanto, la devoción a Jesús Nazareno es lo que es debido a la existencia de la imagen ya mencionada; sin este, físicamente, no tendría ningún sentido todo el bagaje cultural que gira en torno a este. El símbolo es el elemento que acoge y figura al significado.

\section{Según Geertz (2003),}

la cultura es pública porque la significación lo es, uno puede hacer una guiñada (o fingir burlescamente una guiñada) sin conocer lo que ella significa o sin saber cómo contraer físicamente el parpado... La cultura consiste en estructuras de significación socialmente establecidas en virtud de las cuales la gente hace cosas tales como señales de conspiración y se adhiere a estas (p.26).

La cultura es, en general, un bagaje compartido de símbolos y significaciones, que se puede ver que suele estar cargado de complejidad cuando se adentra en la comunidad, en su espacio divino, en lo familiar y lo cotidiano. Al respecto, el padre de la Antropología semiótica Clifford James Geertz (2003) dice lo siguiente:

Los estados de ánimo que provocan los símbolos sagrados, en diferentes épocas y en diferentes lugares, van desde el entusiasmo a la melancolía, desde la confianza en uno mismo al autoconocimiento, desde una corregida y alegre ligereza a una blanca indiferencia, para no hablar del poder erógeno de muchos mitos y ritos del mundo (p.94).

Jesús Nazareno es la imagen que evoca miles de manifestaciones de fe mezcladas con lo natural, que permite descubrir dentro de los izalqueños una parte cognitiva heredada por medio de la tradición oral sobre dicha imagen; y que esto es custodiado por la Hermandad, según Diego Durán (2015). Comenta:

Paralelamente los aromas de ciertas plantas y flores que servían como adorno o fungían como ofrenda contribuían al entorno oloroso de cada fiesta: las especies variaban para reflejar las preferencias de las divinidades, por ciertos perfumes y para subrayar el contraste entre la temporada de lluvias y las secas... El fraile Diego Durán describe un ritual de sahumerio en la sociedad náhuatl cuyo objetivo era invocar a las nubes. Cualquiera que haya sido el fin perseguido por los dones odoríferos, venerar, pedir, agradecer, no cabe duda de que la intención era complacer a las divinidades con aromas que resultaban provechosos, pero también deleitosos.

La flor de corozo y de coyol cumplen una función aromatizante en los ritos de Semana Santa, en el municipio de Izalco, adquiriendo esta una gran relevancia dentro de Hermandad y sobre todo a la imagen de Jesús Nazareno, pues según la población es el aroma de Jesús; si no hay flor no hay velación, por tanto, el carácter de la flor como signo se agrega al plano divino, en el que es la flor misma donde Jesús descansó y anduvo entre las espinas escondido, por lo que su agregación a los actos devocionales permite no solo a los cortadores de la flor, sino también a la población en general sentir las fragancias de la fe; además del aroma que se ofrece a Jesús, también la flor adquiere un valor de canje. 


\section{Método}

La metodología implementada en esta investigación es la endo-etnográfica, debido a las cualidades de los investigadores; La hermandad de Jesús Nazareno es la institución socioreligiosa en la que se centra la investigación, debido a que en ella convergen historias de vida, costumbres, creencias, cosmovisiones y, sobre todo, un punto de partida para la comprensión de la devoción y apropiación de la imagen, la cual forma parte no solo de una tradición, sino que también del entretejido del seno familiar izalqueño; y que a partir de ello es heredada la devoción de generación en generación.

Las técnicas que se utilizaron fueron la entrevista semiestructurada y las historias de la vida, las cuales permitieron la mayor cantidad de recolección de información. Cabe destacar que los entrevistados tienen un nivel de confianza con los entrevistadores debido a que se hicieron visitas previas y por el acompañamiento de las distintas actividades, tanto de la hermandad como de las cofradías. Cabe destacar que uno de los investigadores, Miguel Najo, ha participado dentro de la Hermandad de Jesús Nazareno desde su nacimiento hasta la actualidad, y que su participación es heredada de generación en generación por su familia, que también participa dentro de la Hermandad. En el caso de Francisco Santos, ha participado dentro del marco de cofradías durante más de 4 años, y 3 dentro de la Hermandad, permitiendo así la apertura y confianza con los informantes clave, debido a su permanencia dentro de la comunidad. Sin embargo, hubo algunos informantes que se abstuvieron de participar.

\section{Resultados de la investigación}

\section{La leyenda}

La flor de corozo y la de coyol adquieren un carácter simbólico en los ritos de Semana Santa, aunque su historia se ha perdido en el tiempo y debido a ello surgen inquietudes sobre su participación dentro de los ritos procesionales y de velación dentro de la Hermandad de Jesús Nazareno de Izalco.

Una de las personas que han expuesto ideas sobre el posible origen de esta mítica planta es Edgar Avelar (2018) en su sitio www.izalcopiadoso.net, donde hace referencia a esta planta y la relaciona con los tzutujiles, zotoniles o tz'utujiles, uno de los pueblos ubicados hacia el sur del lago Atitlán. También menciona una leyenda de este grupo étnico sobre el MaNawal JesuKrista, estaba huyendo de unos enemigos después de haber caminado toda la noche; se encontraba en medio del bosque desesperado y cansado; se detuvo en un "punto sagrado", donde había un árbol de palma de corozo.

Figura 1. Ismael sostiene una flor de coyol, la cual será utilizada para la vela de Jesús el Lunes Santo.

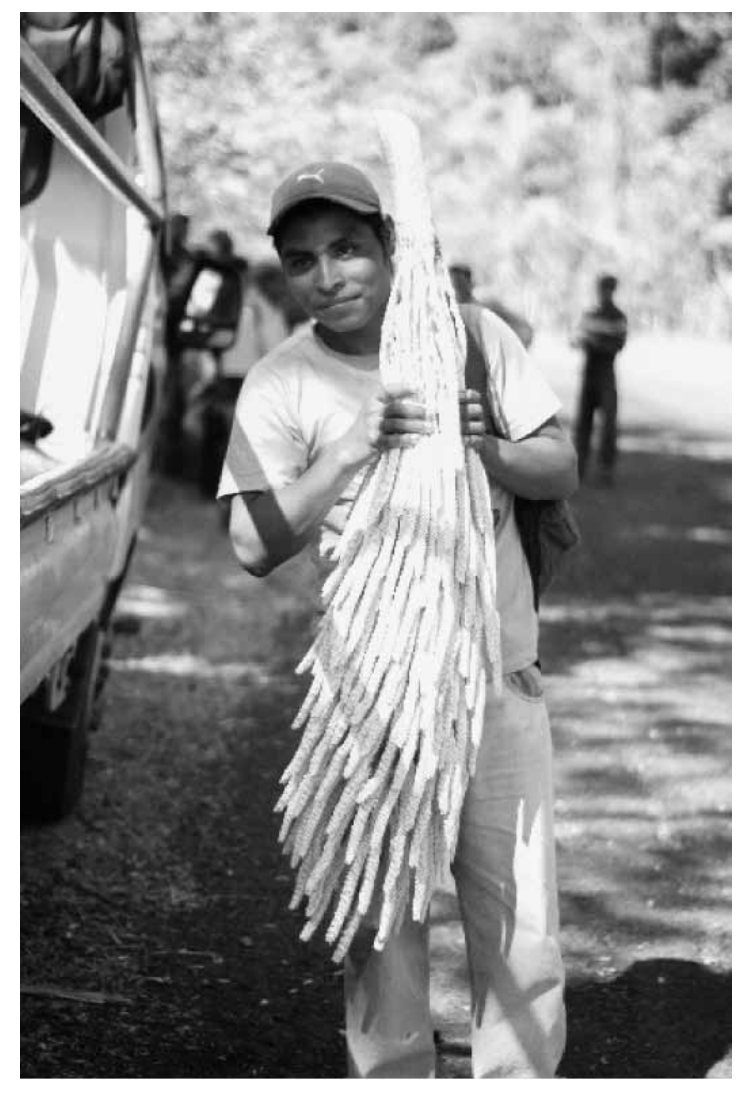

Fotografía cortesía: Miguel Najo

Avelar comenta:

Le habló al árbol diciéndole: "Árbol de corozo, flores de corozo: estoy perdido, estoy cansado; he venido a descansar a tus ramas, a tus brazos; el enemigo está tras de mí, pronto me alcanzarán, pronto me capturarán y me matarán, ya me llegará mi tiempo. Corozo, flores, háganme un favor... proporciónenme un lugar para descansar entre sus ramas, abrásenme un tiempo entre sus brazos, dulce agua, quita la sed de mi boca, quita el polvo de mi cara y de mis pies". 
Entonces, el árbol de corozo le habló a MaNawal JesuKrista diciéndole: “¿Quién te matará mientras yo sea tu trono? Descansa en mis ramas, descansa en mis brazos, deja que el enemigo no te vea mientras yo pueda darte una sagrada protección". Ante esto, narra la historia que MaNawal JesuKrista' le respondió: "De ahora en adelante, tú vas a ser 'la flor más sagrada de las costumbres de mi gente'. Tu blanqueza, será una señal de pureza, tu dulce olor será un recuerdo de mi paso por acá". Entonces MaNawal JesuKrista' se subió al árbol de palma de corozo, se sentó entre sus ramas y descansó. Pero otros historiadores, apuntan que MaNawal fue sacrificado en dicha palmera, ya que sus perseguidores lo capturaron, matándolo en el lugar.

Como se lee en dicho texto, Avelar plantea que la utilización de la planta del árbol bien podría ser de origen mítico y que provendría del MaNawal JesusKrista. Nuevamente el mismo autor menciona:

Debido a este último dato, es que se ha llegado a teorizar que efectivamente esa es la correcta interpretación que los izalqueños debemos dar a la Centenaria Procesión de los Cristos, donde la comunidad indígena, representando a sus cofradías respectivas, nos muestran las imágenes (¿de Cristo?) sacrificadas en cruces foliares, adornadas nada más y nada menos que con flores de coyol y de corozo. Teorización digna de tomarse a consideración.

La teoría que plantea Avelar consiste precisamente en que las flores de coyol y de corozo son utilizadas debido a la leyenda de los tzutujiles; y posiblemente a partir de esa leyenda el corozo y el coyol se utilicen también para representar ese pasaje en las procesiones de los cristos. Otro autor que escribe sobre este tema es Carlos Leiva (2007). En el libro El Rostro del Sincretismo este investigador planeta la misma idea que Avelar, basándose este último en las investigaciones que Leiva había expuesto con anterioridad.

\section{Leiva comenta:}

La flor de corozo debió simbolizar, para los viejos nahuas, lo que significa todavía para los tz'utujiles: "La más femenina en todas las vírgenes munil", es decir, "esclava" de carácter tributario. ¿Será que la entrega que hace cristo de sí mismo, o su sacrificio, fue considerado una cuestión puramente pasiva dentro del pensamiento sincrético de las etnias mesoamericanas?
En ese sentido, el corozo y el coyol, palmeras de la costa entre Tehuantepec y Mizata en El Salvador, solo refrendan la idea del sacrificio martirial de Cristo. Pues, mientras que en la tradición t'zutuhil de los atitecos es capturado "mientras se esconde en su árbol de corozo o, como dicen algunos, "una flor de corozo", entre los izalcos de Ataco es capturado tras ser delatado por los gritos de un perico (¿alguna relación con la guacamaya, "falso sol" de los mayas?), que denuncian su escondite en una de las palmeras más altas del corozal, suponiendo que fue crucificado después, sobre cualquiera de las que allí había.

Nuevamente aparece este elemento de relacionar la parte mitológica de los t'zutuhiles con el corozo en este caso. Resulta interesante dicha relación, ya que en parte se intercambian ciertos elementos en Izalco. Sin embargo, se debe de indagar más sobre dicho tema.

\section{El arte de cortar la flor}

Cristina Vázquez (2018) comenta: “Esa flor tiene su misterio, porque es donde anduvo él en su infancia; se anduvo escondiendo en medio de esos espineros, por los judíos, vá. Pero, como le repito, él no es que no se pudiera defender, pero como él tenía que enseñarnos a sufrir".

En cuanto a la flor, existen dos variedades el corozo y el coyol. La palma del coyol es una palmera cargada de espinas desde el tronco hasta las palmas, incluso la flor misma está cargada de espinas muy finas que, según algunos informantes, son difíciles de sacar si una llega a meterse en la mano; y se cree que las espinas caminan dentro del cuerpo y llegan al corazón. A diferencia del corozo, que la palmera no tiene espinas y por eso es más accesible la corta de esta, además de que su pacaya es de mayor tamaño que la del coyol. Cabe decir que se emplea la misma técnica en cuanto a la corta de la flor de ambas palmeras.

La documentación de la corta de la flor de coyol y de corozo surge gracias a la invitación del presidente de la Hermandad de Jesús Nazareno; y es así como se conoce ese arduo proceso de la corta de esas flores. A las seis de la mañana del Jueves de Dolores, del presente año, se reúnen alrededor del templo algunos miembros de la Hermandad y otros hombres que no lo son, pero que llegan a apoyar durante dicha actividad. Ellos serán los encargados de realizar la corta de las palmas y flores, que se realiza en el municipio de Santa Isabel Ishuatán. En un viaje de aproximadamente una hora se llega a una zona a la orilla de la carretera, y en 
un terreno laderoso se encuentran las flores de corozo. Se ingresa a través de veredas empedradas y muy boscosas, además hay mucho arbusto de ishcanal, que abunda en la zona.

\section{Figura 2. Cofrade sostiene una flor de corozo,} obtenida en Santa Isabel Ishuatán.

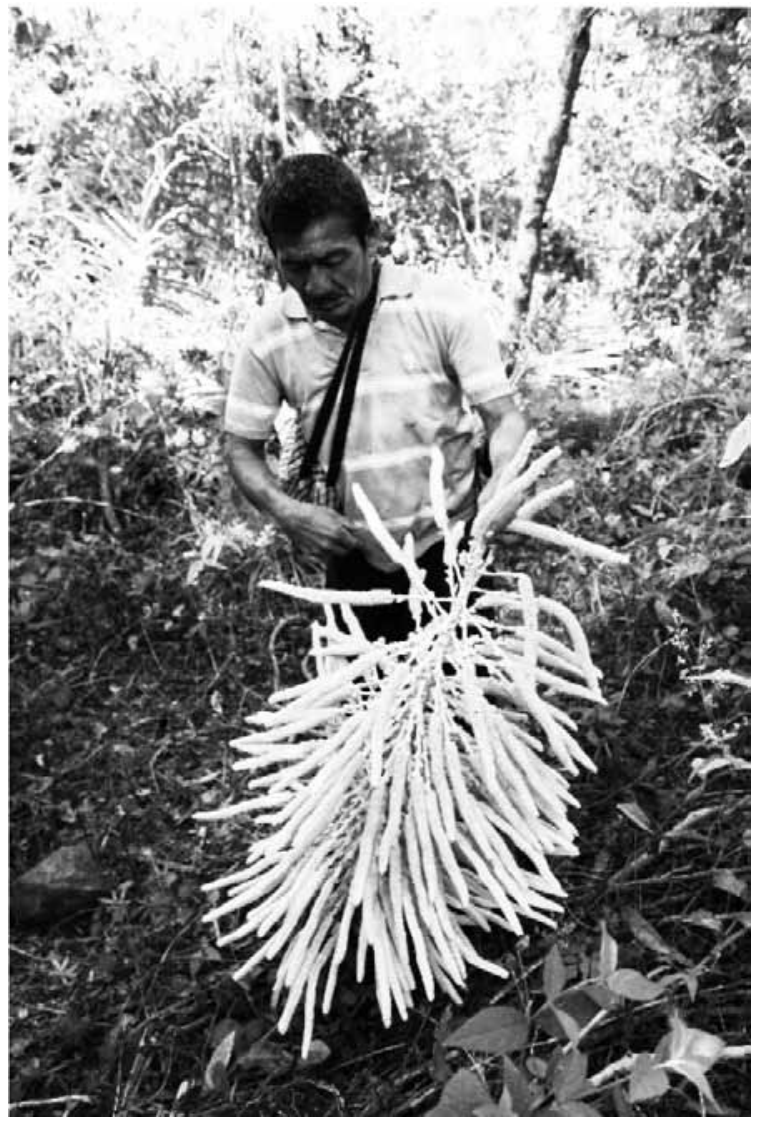

Fotografía cortesía: Miguel Najo.

Al llegar, en lo más alto de las laderas se encuentran abundantes las palmeras de coyol. Los cortadores se dividen en grupos: Ios que cortarán la flor y los que los sostendrán. Para obtener la flor, se tiene que subir en la palmera de coyol, que está toda cubierta de espinas de gran tamaño; pueden medir hasta 15 centímetros o más. Para realizar tal actividad es necesario usar calzado adecuado.

El proceso de la corta parece sencillo, pero en realidad es complejo y arriesgado. Al inicio la persona que realiza la corta de la flor lanza el plomo: un lazo delgado que en la punta lleva un pequeño cubo de plomo; y lleva amarrado el lazo que usará el cortador, este se lanza de forma que caiga al otro lado de la palmera, pero debe de caer justo a la mitad de esta. Después de eso, el cortador procede a amarrarse un lazo en la cintura y es jalado hacia arriba por tres hombres. Luego, poco a poco el cortador va subiendo mientras los otros tres lo van jalando hasta que el cortador llegue a la punta de la palma.

Don Manuel Purito Latin comenta:

Cuando nosotros ya estábamos aquí, íbamos a cortar la flor por Caluco. Antes había bastantes (...) Lito Calzadilla, el papá tenía una carreta; él la llevaba y otro señor llevaba un caballo. Ahí poníamos las pacayas y los cojollos de las palmas y las flores. Yo no me subía. Como eran bajitos los palos, con una vara jalábamos y caían; como solo con un cuchillo o con el corvo cortaba cian. No andaban trepando; como los palos bajitos. No es como hoy. Les cuesta... Bien bajos los palos.

La flor de coyol suele ser formada por granitos que revientan en diminutas flores, en cambio el corozo es una flor a manera de pétalos y que es la que más olor produce, además es que más crece dentro de la pacaya que la envuelve.

\section{Figura 3. Espina de la palma de coyol, que llega a medir hasta 15 centímetros de largo.}

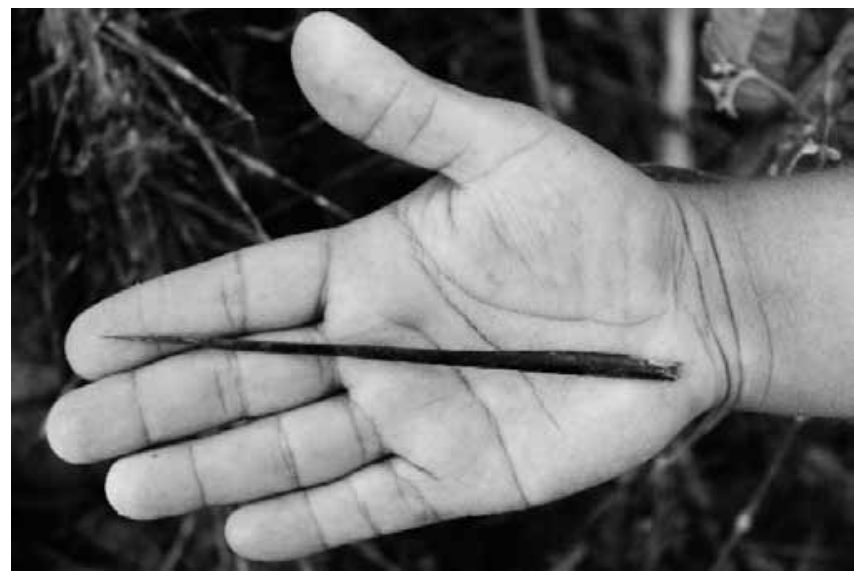

Fotografía cortesia: Miguel Najo.

Cuando los cortadores se encuentran arriba de las palmeras, cortan las pacayas de las flores, que están cubiertas de espinas; $y$ uno de los acompañantes se encarga de rasparlas con un machete para eliminar las espinas.

Después de haber realizado las cortas de las pacayas en el transcurso de la mañana, se procede a llevarlas al camión donde también se llevan palmas que serán utilizadas para 
elaborar las cruces que adornarán los cristos el Jueves Santo. El segundo lugar donde se llega es un terreno en la altura del municipio donde se encuentran las palmeras de corozo; estas son más fáciles en cuanto al corte y a la bajada de las pacayas, pues no tienen espinas.

Para finalizar la faena, se reúnen los cortadores; y un reducido comité que se ha organizado, por parte de la Hermandad, se les reparte a todos unos almuerzos, que puede ser sopa de res. Luego de ser cortada la flor y transportada hábilmente hacia el camión, se procederá a entregarla en el templo de Jesús Nazareno, todo el material obtenido, entre flores y palmas. Las flores tendrán la función como elemento de canje. Durante la vela de Jesús Nazareno el Lunes Santo y en las demás velaciones, a las personas, al dar su ofrenda, se les entrega, por medio del encargado de cuidar a Jesús, una flor, ya sea de coyol o de corozo, como constancia de su aporte a la Hermandad. Por último, algunas pacayas y palmas se reparten a varios representantes de las distintas cofradías, para que sean utilizadas para adornar a los cristos en la procesión de Jueves Santo.

Dicha flor es portada a la vista pública, esto hace merecedor, a quien la porta, de una porción de chilate y dulce, además de tener la satisfacción de haber contribuido para la realización de la fiesta de Jesús. Luego esa flor no debe votarse, ya que está bendecida por Jesús Nazareno. Como se muestra, la flor cumple una función muy importante dentro de los rituales de Semana Santa.

\section{Las crucitas}

Las crucitas son elaboradas de palmas de coyol o de corozo; se entrelazan formando una cruz, que es utilizada principalmente como un 'contra' o defensor de vientos malos encargados de destruir tanto la casa como la siembra. La crucita de palma suele ser bendecida el Domingo de Ramos, o pueden ser de las que portan los cristos.

El Domingo de Ramos es el día en que se da apertura al inicio de la Semana Santa, siendo uno de los días más esperados por la comunidad en general por la obtención de las palmas bendecidas, pues en torno a ellas gira un enorme significado ritual adquirido no solo socialmente, sino por la condición de elemento o signo bendecido por la divinidad.

El Domingo de Ramos, las parroquias de Dolores y de Asunción de Izalco se reúnen en puntos estratégicos o significativos para la comunidad. En el caso de la primera, la procesión parte del templo de Jesús Nazareno y Asunción, de la ermita de la Virgen de los Remedios. Antes de salir, el párroco lee un texto bíblico, narrando el pasaje de la entrada triunfal de Jesús en Jerusalén, para luego bendecir con agua bendita los ramos de palma de coyol; algunos son comercializados por vendedoras, demostrando su ingenio tejido de la palma. En otros casos es la misma parroquia la que suministra los ramos; o particularmente las cofradías son las que proporcionan cruces de palma previamente bendecidas por la imagen titular y con el agua bendita.

\section{Figura 4. Damián Torres y Jairo Domínguez, Niños Celadores de Jesús a los pies del Cristo de San Sebastián, nietos de la mayordoma. Destáquese el cristo adornado con flor y cruces de palma.}

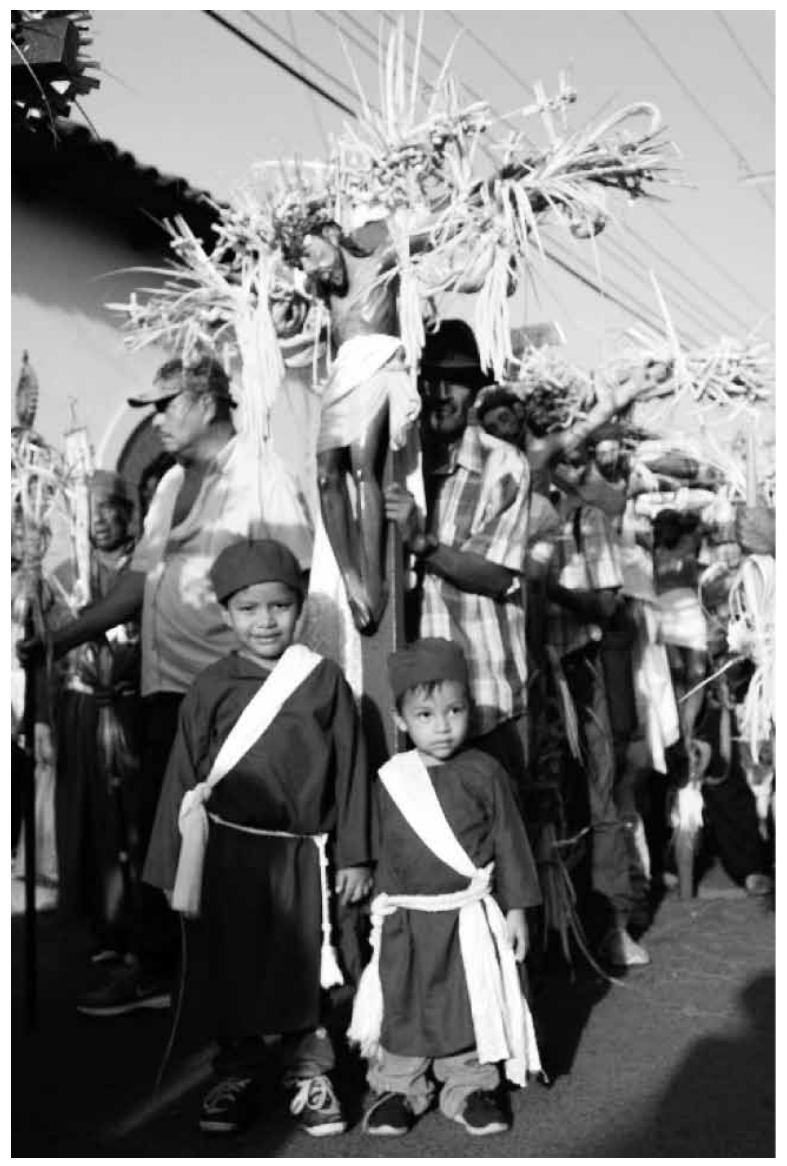

Fotografía cortesía: Miguel Najo.

Emma Torres (2018) dice lo siguiente:

El domingo es la bendición de las palmas. Cuando estaba mi papá (don Carlos Díaz, mayordomo de San Sebastián), íbamos a bendecir las palmas; hacía el 
manojo de crucitas, las íbamos a bendecir y le dábamos a la gente (de parte de la cofradía de San Sebastián). Después de la misa se regalaban; ni nos alcanzaban.

Dicha actividad, en la que las cofradías obsequiaban cruces de palmas de coyol, ya no es tan común. Sin embargo, hay algunas que aún mantienen la costumbre de obsequiarlas, ya que las utilizan para la protección de los huracanes

Juana Mora (2018) comenta:

Pues uno que cree en las cosas de Jesús y en las palmitas que dicen que cuando vienen las tormentas, se ponen. Nosotros siempre ponemos en la puerta, porque cuando dicen que vienen las tormentas bien fuertes hay que tener sus crucitas de las palmitas bendecidas de Jesús. Carlos (QDDG), también cuando él lo hacía ... iba a poner en las milpas, como el hacía milpa, cuando venían las grandes tormentas no le votaban los elotes de la milpa.

Estas cruces son elaboradas con antelación, aproximadamente cuatro días antes del Jueves Santo, en el caso de la procesión de los Cristos, y cuatro días antes para compartir el Domingo de Ramos. Es común que durante la procesión de los cristos los cofrades lleven manojos de cruces para obsequiar a quien los pida. En otros casos, los fieles toman directamente del Cristo una de las cruces, debido a la fe en que se dice que al tener contacto con la divinidad lo material toma parte de esa divinidad, por tanto son las cruces más preciadas.

\section{La velas de Jesús}

Las velas son una acción que tiende a variar de significados, según la situación en la que se esté utilizando el concepto, pues las velas de Jesús son una variante de las velas de difunto; las velas de Jesús se rigen en velar a Jesús Nazareno, que se encuentra en una casa representando un pasaje bíblico, donde a la vez se reparte chilate y dulce. Las velas de difunto son otro aspecto, pues se está velando a una persona difunta por medio de la familia doliente. En este caso nos referimos propiamente a las velas de Jesús Nazareno.

Delfina Latin (2018) comenta:

Yo pienso que las velas son los lugares donde Jesús anduvo, ¿verdad? Yo así lo pienso que eso representa; los lugares que el anduvo predicando. Mire cuántos milagros hizo él. Vaya y acuérdese cuando le dijo a Zaqueo, el que era recaudador de impuestos... Entonces el Señor le dice: "Hoy cenare en tu casa". Por eso dice él: "El que habrá la puerta, entraré. Yo cenaré con él y él conmigo.

Delfina Latin propone que las velas en sí son un momento en el que Jesús entra a la casa de los que le abren la puerta, los cuales son los oferentes que solicitaron su llegada; y que estos gozarán de la visita de la imagen, que estará con la familia en un momento íntimo en el que la casa del oferente se vuelve el lugar donde se encuentra el altar un Sancto Sanctorum, donde se posará la divinidad misma.

A partir de las cinco de la mañana, se abren las puertas del templo y las personas empiezan a llegar desde tempranas horas. Durante la mañana, tarde y noche, las personas llegan a visitar la imagen del Nazareno. En su mayoría se acercan a apreciar el altar y dan su ofrenda. Después de este acto, dos miembros de la Hermandad proceden a hacerle entrega de una flor de coyol o de corozo en señal de agradecimiento de la ofrenda que ha realizado. Posteriormente pasan a degustar el tradicional chilate con el dulce (este puede ser de papaya, mango, jocote, plátano o chilacayote).

Figura 5. Altar de velación de Jesús Nazareno, acompañado de la imagen de la cofradía de la Virgen de Belén. Oferente: Juana Mora. Tema: "Dejad que los niños vengan a mí", cuarto domingo de cuaresma.

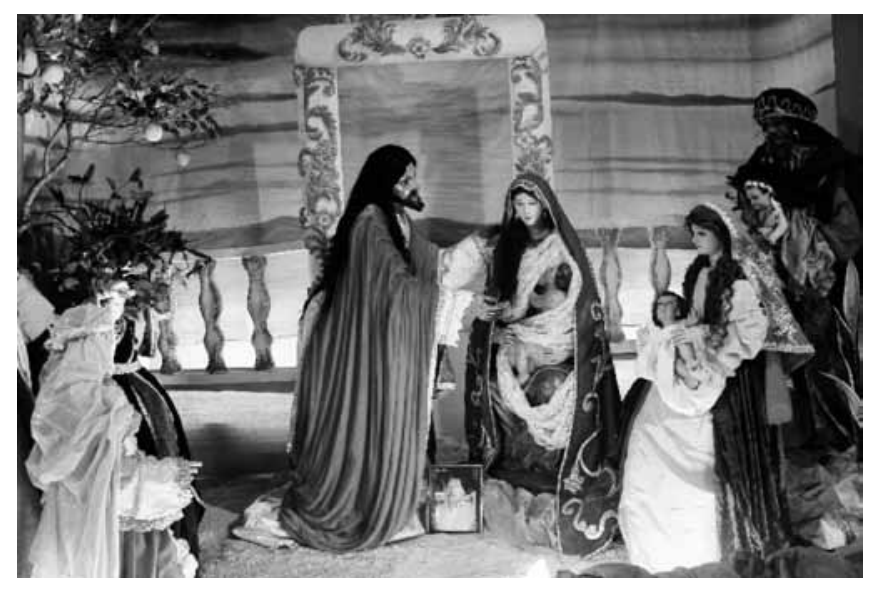

Fotografía cortesía: Miguel Najo. 


\section{Conclusión}

La flor de corozo y de coyol son símbolos cargados de significado a partir de su utilidad dentro de las actividades mágico religiosas que permiten así expresar y contribuir a la humanidad de Jesús Nazareno, que siente y expresa su agrado por medio de sus facciones. El entretejido simbólico que rodea la flor y su palma da así un conglomerado de símbolos y significados que se derivan a través de estos símbolos primarios, como es el caso de la palma de corozo, que se utiliza para los ramos del Domingo de Ramos y para las cruces de los cristos; la flor sirve también como aromatizante en la tradición y como elemento de canje en la cocina de la Hermandad.

El arte de la obtención de la flor es un ritual en el que el mismo cortador se integra; en el que el sacrificio, las heridas y la habilidad permiten al cortador llegar al elemento simbólico de conexión entre el pasado y el presente; y que además es un elemento infaltable, pues es la misma divinidad y las leyes de la costumbre las que exigen su presencia.

\section{Referencias}

Aguirre Baztán, A. (1995). Etnografía. En A. A. Baztán, Etnografía. Metodología cualitativa en la investigación sociocultural. (pp. 3). Barcelona, España: Marcombo.

Avelar, E. (2018). Izalco Piadoso. Recuperado de http://www. izalcopiadoso.net/index.html

Dupey Garcia, É. (2015). Olores y sensibilidad olfativa en Mesoamérica. Arqueología Mexicana, (135), 24-29. Recuperado de https://arqueologiamexicana.mx/ mexico-antiguo/olores-y-sensibilidad-olfativa-enmesoamerica

Geertz, C. (2003). Interpretación de las culturas. Barcelona, España: Gedisa.

Leiva Cea, C. (2007). Rostros del sincretismo: guía al plano místico de los antiguos Izalcos. San Salvador, El Salvador: Dirección de Publicaciones e Impresos 